\title{
The role of senescence-associated secretory phenotype (SASP) in cellular senescence
}

\author{
Filda Vionita Irene de Lima $^{1} \mathbb{D}$, Novi Silvia Hardiany ${ }^{2 *} \mathbb{D}$ \\ ${ }^{1}$ Master Program in Biomedical Sciences, Faculty of Medicine, Universitas Indonesia, Jakarta 10430, Indonesia \\ ${ }^{2}$ Department of Biochemistry \& Molecular Biology, Faculty of Medicine, Universitas Indonesia, Jakarta 10430, Indonesia \\ *Correspoding author: Jl. Salemba Raya No. 6, Central Jakarta 10430, phone (021) 31930373, Email: novi.silvia@ui.ac.id/ \\ novish98@gmail.com
}

\begin{abstract}
Cellular senescence is one of the defense mechanisms of cells against oncogenic signals by permanently stopping the proliferation of the cell. Senescence cells show a similar characteristic, one of them is senescence-associated secretory phenotype (SASP). SASPs secrete various components, divided according to the type of molecule secreted and based on their mechanism of action against target cells. The main components of SASP are pro-inflammatory mediators. SASP performs dual and contradictory roles, which concurrently provides beneficial effects such as tumor suppression due to the termination of proliferation, recruitment of immune cells, and tissue repair. On the other hand, SASP produces detrimental effects on cells undergoing the senescence process as well as cells in the surrounding environment by increasing tumorigenesis. This review article explains the various components of the SASP, the role of SASP in the inflammatory process, tumor suppression, and tumorigenesis.
\end{abstract}

Keywords: cellular senescence, senescence-ssociated secretory phenotype, tumor suppression, tumorigenesis, pro-inflammation

\section{Introduction}

Cellular senescence is defined as a state of proliferation arrest in which cells stop dividing irreversibly. Senescence is the fate of cells triggered by a response to DNA damage and oncogenic stress. All somatic cells that can replicate may become senescent cells [1-3]. Hayflick and Moorhead proposed the cellular senescence mechanism, in which normal human cells can reach a phase of limitation in replication and becoming senescence cells in vitro. The causes of senescence in cells vary widely. For example, continuous replication results in telomere shortening, causing replicative exhaustion which induces the DNA damage response (DDR) and terminates the cell cycle to repair the damage [4]. Genetic factors, exposure to oxidative stress, inflammation, poor lifestyle (including smoking, overnutrition, and lack of physical activity), psychological stress, and oncogene exposure strongly influence the process of telomere [5].
Exposure of cells to oncogene signals tightens the action of proteins that play a role in cell cycle checkpoints. Surprisingly, cancer therapy can cause an increase in the number of senescence cells, which targets the DNA damage of cancer cells and the surrounding normal cells [6]. Senescence cells halt a cell cycle so that damage is not inherited in the replicated cells. Other causes of senescence such as chromatin structure caused by anti-cancer therapy, mitochondrial damage, oxidative stress, wound healing process, and autocrine stimulation obtained from senescence-associated secretory phenotype (SASP) [7,8].

Senescence cells undergo stable cell cycle arrests, leading to unresponsive cells against mitogenic signals as a mechanism to prevent the replication of cells with DNA damaged [9]. Most senescent cells are in the G1 phase of the cell cycle $[2,10]$, shown by the expression of the $p 53$, which is essential in the cell cycle checkpoint. Cells that 
experience senescence in the G1 phase are unable to make the transition to $\mathrm{S}$ phase. However, the synthesis of molecules and cellular components continues to occur resulting in the increase in cellular morphology $[11,12]$. Termination of the cell cycle at senescence in the G1 phase distinguishes senescent cells from the cells that undergo final differentiation and quiescence, in which those cells undergo termination at the G0 phase of their cell cycle. Typically, the cell cycle can achieve completion by activating the $\mathrm{p} 53 / \mathrm{p} 21^{\mathrm{CIP} 1}$ and $\mathrm{p} 16^{\mathrm{INK} 4 \mathrm{~A}} / \mathrm{Rb}$ tumor suppression pathways. Activation of both pathways prevents cancer-induced apoptosis and tumor cell proliferation by inducing cell cycle arrest $[8,13]$.

Every somatic cell that can divide is possible to become a senescence cell. Cell senescence from any cell type showed the same phenotypic characteristics. Morphologically, they are flat, enlarged, and multinucleated [3]. In addition to cycle cell arrest, they show unresponsiveness towards growth factors, resistance against apoptosis, increased protein synthesis, increased glycolysis that causes metabolic shifts, decreased fatty acid oxidation, increased reactive oxygen species (ROS), as well as senescence-associated heterochromatin foci formation and a senescence-associated secretory phenotype (SASP) [1-3,14].

Senescence-associated secretory phenotype (SASP) is highly dynamic and multi-step process [9]. SASP has special characteristics and can be distinguished from other cell types. The number of SASPs was found to increase with age and correlate with multiple age-related diseases pathogenesis [15]. Elevated levels of SASP in the circulation are associated with the increase of biological age accompanied by a decrease in the cellular function of the human body [16]. SASP secretes various molecules in the tissues such as cytokines, chemokines, growth factors, proteases, and lipids. The cause of a senescence process determines the secreted molecules components that can differ from one cell to another [17].

Senescence cells form SASP to protect themselves from growing and developing into cancer cells. The secreted molecules can interact with the surrounding microenvironment, causing autocrine and paracrine effects. SASP can stimulate nuclear factor- $\kappa B$ (NF- $\kappa B$ ) signaling to prevent apoptosis [1]. On the other hand, SASP produces detrimental effects on cells undergoing the senescence process as well as cells in the surrounding environment by increasing tumorigenesis. These diverse effects are caused by the enermous diversity of compounds secreted by senescence cells. Therefore, this article explains the regulation of SASP, various components of SASP, and the impact of SASP through the inflammatory process, tumor suppression, and even tumorigenesis.

\section{Regulation of SASP}

SASP is regulated at both transcriptional and post-transcriptional levels. Nuclear factor- $\kappa \mathrm{B}$ (NF- $\kappa \mathrm{B})$ is the main regulator of the expression of SASP components such as various types of interleukins and chemokines. CCAAT/enhancerbinding proteins (C/EBP) are also known to regulate the expression of interleukine-6 (IL6) [18]. C/EBP consists of transcription factors part of the basic zippered leucine superfamily (bZIP), responsible for many cellular processes, including cell survival, learning and memory, lipid metabolism, and cancer progression. C/EBP, as well as NF- $\kappa \mathrm{B}$, can respond to stress signals such as cytokines, genotoxic agents, or physiological stresses. Thus, the transcription factors NF- $\kappa B$ and C/EBP are the primary regulators of SASP expression [19].

At the post-transcriptional level, SASP is stimulated by DNA damage response (DDR). DDR activates ataxia-telangiectasia mutated kinase (ATM kinase) that regulates NF- $\kappa$ B. ATM kinase forms a complex with NF-KB essential modulator (NEMO). Due to DDR stimulation, NEMO from the nucleus is released into the cytoplasm [20]. NEMO then activates the TGF $\beta$ activated kinase 1 (TAK-1) complex and inhibitory kappa B kinases (IKK), which are responsible for dissociating inhibitory kappa B (ІкB) proteins. The IкB protein is part

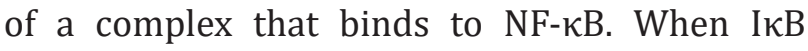
protein is released, NF- $\kappa \mathrm{B}$ is active and triggers 
the expression of cytokines, chemokines, and other pro-inflammatory molecules [21].

Due to DDR and oxidative stress, p38 activates the $\mathrm{p} 16 \mathrm{INK} 4 \mathrm{~A} / \mathrm{Rb}$ signaling pathway that mediates cell cycle arrest. In the SASP regulatory function, p38 activates mitogen- and stress-activated kinase 1 and 2 (MSK1/2). MSK1 and MSK2 kinase then phosphorylate $\mathrm{p} 65$, one of the NF- $\kappa \mathrm{B}$ transactivation subunits [22]. This process initiates the expression of various SASP components. Another genetic stress triggers receptor-interacting serine/threonineprotein kinase (RIP1) that mediates the formation of the NEMO complex. p53-induced protein with death domain (PIDD) and RIP1 promotes NEMO release from the nucleus to the cytoplasm [23].

Extracellular inflammatory signals are recognized by inflammasomes, a complex consisting of the receptor and several proteins. The binding of signal molecules in several types of cells, including senescence cells, can activate these receptors and trigger important intracellular signaling pathways, such as the mitogen-activated protein kinase (MAPK), Janus kinase (JAK)-signal transducer and activator of transcription (STAT), and NF-кB pathway [24]. One of the receptors on the inflammasome is a retinoic acid-inducible gene I (RIG-I). RIG-I is activated by induction of cellular stress due to irradiation, senescence, viral infection in human fibroblasts and endothelium, thereby increasing the secretion of IL- 6 and IL-8. RIG-I is a pattern recognition receptor that plays a role in infection recognition. TGF- $\beta$ is a cytokine that controls cell hemostatic activities such as proliferation, differentiation, apoptosis, and immune responses. TGF- $\beta$ also stimulates IL-8 secretion [25].

Other studies suggest that GATA4 involve in SASP regulation. GATA is typically degraded through p62-mediated autophagy. Activation of ATR and ATM by DDR stimulation leads to dysfunction of p62, a protein that targets various autophagy substrates in the cells. p62 mediates the binding of these substrates to the autophagosome's inner membrane and is ready to be degraded via the autophagy mechanism [26]. In senescent cells, the autophagy process is suppressed, so GATA4 becomes stable in cells. GATA4 accumulation in cells initiates NF- $\mathrm{BB}$ activity [27].

p53 is known to inhibit NF- $\kappa B$ via wild-type p53-induced phosphatase 1 (WIP1). ATM, p53, and p38 were inhibited by WIP1 [28]. Klotho protein, known as an antiaging protein, can inhibit RIG-I, so NF- $\kappa \mathrm{B}$ activation is inhibited and reduces IL-6 expression [29]. Another pathway that directly inhibits NF- $\mathrm{KB}$ activation signals is through the p16INK4A and p14ARF pathways. p16INK4A is a cyclin-dependent kinase inhibitor with ankyrin repeats that bind p65 and protein I $\mathrm{BB}$. p14ARF inhibits by phosphorylation of p65 in the p65 transactivation domain so that it interferes with the NF- $\mathrm{BB}$ activation signal $[30,31]$.

\section{Classification of SASP}

SASP is categorized based on the molecule type and the mechanism of action to initiate SASP activity (Table 1).

Table 1. Classification of SASP

\begin{tabular}{ll}
\hline \multicolumn{1}{c}{ Molecule type } & Mechanism of action \\
\hline 1. Soluble signaling factors & 1. Receptor-requiring \\
2. Secreted proteases & SASP \\
3. Secreted insoluble proteins & $\begin{array}{l}\text { 2. Direct-acting SASP } \\
\text { 4. Non-protein secretion }\end{array}$ \\
& $\begin{array}{l}\text { 3. SASP regulatory } \\
\text { factors }\end{array}$ \\
\hline
\end{tabular}

\section{Classification of SASP based on the molecule type}

\section{Soluble signaling factors}

The main components of this group are several types of interleukins (such as IL-6 and IL-1), chemokines, and growth factors. The type of interleukin depends on the type of cells undergoing senescence. IL-6 is widely secreted in human and mouse keratinocytes, melanocytes, monocytes, fibroblasts, and epithelial cells. IL-1 is widely excreted in senescence endothelial cells and fibroblasts, as well as epithelial cells induced by chemotherapy [32].

$\mathrm{C}-\mathrm{X}-\mathrm{C}$ motif chemokine ligand (CXCL) and C-C motif ligand (CCL) are chemokines widely expressed 
by senescent cells. CCL generally overexpressed by senescent cells includes CCL-1, CCL-2, CCL-8, CCL-13, and CCL-26. Senescent liver stellate cells, as well as prostate and skin fibroblasts, produce CCL-7, while senescence prostate fibroblasts released CXCL-4 and CXCL-12 [19,33].

Other components of soluble signaling factors are growth factors, for example, insulin-like growth factor (IGF), which is widely secreted by senescence endothelial, epithelial, and fibroblast cells. In these cells, various types of IGF-binding proteins (IGFBP) are secreted at high levels, such as IGFBP-2, -3, -4, -5, -6, and -7, along with insulin-like growth factor binding proteinrelated proteins 1 and 2 (IGFBP-rP1 and -rP2) as regulatory proteins. In addition to these components, several soluble components increase their secretion in senescence cells, including cytokines colony-stimulating factors (CSFs), osteoprotegerin, prostaglandin E2 (PGE2), and the enzyme cyclooxygenase-2 (COX-2), all of which are pro-inflammatory molecules $[19,33]$.

\section{Secreted proteases}

The main effects of the proteases secreted by the senescence cell are releasing cell membrane proteins to produce soluble membrane receptors, degrading signaling molecules, and degrading ECM processing [16]. Matrix metalloproteinases (MMPs), serine proteases, and the compound that function as regulators of the plasminogen activation pathway are examples of proteases secreted by senescent cells. Groups of MMPs such as stromelysin-1 (MMP-3) and stromelysin-1 (MMP-10) are secreted by senescent fibroblasts of humans and mice. MMP- 1 and MMP-3 regulate the activity of soluble factors of SASP. An example of these regulations is the breakdown of CCL and CXCL. Other components of proteases are serine and regulators of the plasminogen activation pathway, for example, urokinase plasminogen activators ( $\mathrm{UPA}$ ) or tissue-type plasminogen activators (tPA) and their receptors, urokinase plasminogen activators receptor (UPAR), and plasminogen activator inhibitors 1 and 2 (PAI 1 and 2) [19,33].

\section{Secreted insoluble proteins}

The insoluble protein secreted by senescent cells is fibronectin, a glycoprotein found on the surface of cells, plasma, and other body fluids. Senescent cells in culture and in vivo showed fibronectin expression. Fibronectin interacts with surface receptors of the cell, such as integrins, and causes cell adhesion, growth, and migration [19].

\section{Non-protein secretion}

The components produced in this group include nitric oxide (NO), reactive oxygen species (ROS), and endothelial nitric oxide synthase [33,34]. These components result from metabolism changes in the senescent cells which can affect the adjacent cell.

\section{Classification of SASP based on the mechanism of action}

\section{Receptor-requiring SASP}

The components in this group are soluble signaling factors such as interleukins, chemokines, and growth factors. These signaling molecules bind to their receptors then activate intracellular signal transduction pathways. For instance, IL-6 is upregulated in DNA damage and oncogene-induced senescence, while IL-6 expression is upregulated by IL-1 released from senescent cells [35]. It shows that the autocrine activity of the expression of the secreted SASP components plays a vital role in cellular senescence. The chemokines and growth factors such as hepatocyte growth factor (HGF), fibroblast growth factor (FGF), transforming growth factor $\beta 1$ (TGF $\beta 1$ ), and granulocyte-macrophage colony-stimulating factor (GM-CSF) also bind to their receptors to activate the signaling process. All cells that express those receptors are targets of the SASP components. Therefore, senescent cells that secrete SASP also be targets whose effects can worsen or protect cells from senescence development $[2,27]$.

\section{Direct-acting SASP}

The SASP components included in this group are mostly MMPs and serine proteases. These 
components modulate the environment around senescent cells by using their proteolytic activity to break down extracellular matrix (ECM) and cell membrane proteins. It causes damage to the molecules that carry the signal. Other components in this group are non-protein components such as ROS and NO.

\section{SASP regulatory factors}

Examples of SASP regulatory factors are tissue inhibitors of metalloprotease (TIMPs), plasminogen activator inhibitors (PAI), and insulin-like growth factor-binding proteins (IGFBPs). TIMP is highly induced in response to various cytokines and hormones [36]. TIMP works by inhibiting activated MMPs. PAI-1 has a significant function as an inhibitor of tPA and UPA in the regulation of fibrinolysis. In addition, PAI-1 also inhibits the invasion of malignant cells by inhibiting the activity of MMPs [37]. IGFBP is a protein transporting IGF to target cells that has a role in modulating age-related diseases $[27,38]$.

\section{Roles of SASP}

The role of the SASP is like a double-edged sword. The molecular compounds secreted by senescence cells (SASP) play an essential role, especially as a response to preventing the inheritance of damaged genetic material such as cancer cells formation. In addition, it also acts as a signaling mechanism for the immune system to eliminate the damaged senescence cells. However, most molecules secreted are pro-inflammatory mediators, which harm the microenvironment, both for normal and senescent cells surrounding them and for the interstitial tissue in that area. It can trigger tissue damage and induce the pathogenesis of various diseases, particularly those associated with agerelated diseases and conditions associated with the elevation of cellular senescence.

\section{The physiological role of SASP}

\section{Tumor suppression}

Several SASP components such as IL-6, IL-8, and IGFBP7 can promote cell growth and development inhibition. In cancer cells, the genes encoding the cytoplasmic proteins RAS and BRAF, the transduction of growth factors signals to the intracellular, are disrupted. The presence of oncogenic signals from RAS and BRAF activates IL-6, IL8, and IGFBP7 to suppress cell growth. Increased RAS in ovarian fibroblasts also triggers the secretion of CXCL 1 to suppress cell growth. IL-6 and IL-8 suppress tumor cell growth by activating the transcription factors NF- $\kappa B$ and C/EBP- $\beta[39,40]$. A study using fibroblasts from mice embryos transfected by retrovirus as vectors carrying genes that decrease the expression of PAI 1 and p53 suppressor genes, were found to increase the number of colonies in fibroblast tissue in p53 suppression compared to fibroblast colonies with decreased PAI expression [41]. It is known that PAI-1 has a direct target of action on p53. PAI is a protease inhibitor for uPA, which functions in the cell cycle process to encourage the progression of replication from the G1 to $S$ phase through mitogenic signals provided by growth factors [42].

\section{Immune clearance}

SASP components are pro-inflammatory molecules that recruit immune cells. The role of SASP in the recruitment of the immune cells aims to eliminate the senescence cells themselves. Besides that, they also eliminate cells that express oncogene signals in the environment around the senescence cell. Immune cells recruited in this process are mainly natural killer cells, macrophages, and $\mathrm{T}$ cells $[33,39]$. The immune system decreases in the elderly; therefore, the elimination of senescent cells and surrounding tissues does not work correctly.

Moreover, many senescent cells accumulate over time in the elderly; therefore, the immune system is unable to perform its function. This impaired immune clearance process is also related to other SASP components namely MMPs. MMPs can degrade ligands and receptors on immune cells and their target cells. For example, it degrades NK cell ligands and receptor proteins on cell senescence. Therefore senescent cells can escape from the body's immune response $[33,43]$. 


\section{Tissue repair}

In wound healing, fibrosis is required to restore tissue construction. However, excessive fibrotic tissue can replace normal tissue causing adverse effects [44]. Under normal conditions, type 2 immunity is directly responsible for tissue regeneration and repair. Type 2 immunity is mediated by various immune cells such as IL-4 and IL-13 activated macrophages. Persistent activation of this tissue repair mechanism can lead to tissue fibrosis and contribute to various fibrotic diseases in some organs, mainly the liver and lung $[45,46]$. In an experimental study using a skin wound model in mice, the senescence process was induced by a signal cascade from binding the cellular matrix protein, cellular communication network factor 1 (CCN1), to its receptor. This induces growth arrest and expression of the gene encoding SASP. In this experiment, it appeared that the wound repair of wild-type mice induced by CCN1 caused the fibroblasts to undergo senescence and expressed more antifibrotic genes than the mutated CCNI gene-mice. As the final result, the wound healing process in CCN1-induced mice has less fibrotic tissue $[44,47]$. It is known that VEGF, which is also a component of SASP, plays a vital role in CCN1 activation by activating Yes-associated Protein (YAP), a transcription coactivator of the CCN1 gene [46].

\section{The pathological role of SASP in degenerative phenotypes}

The inflammatory factors secreted by senescent cells are closely related to degenerative phenotypes and diseases. The secreted SASP destroys the network structures necessary for normal functioning. Senescence fibroblast in the breast secretes MMPs that damage alveoli cells, causing interference in milk production. This condition is suspected of contributing to age-related changes in breast morphology $[2,19]$. The senescent smooth muscle cells in pulmonary arteries secret SASP such as IL-6, IL-8, and various ECMs that affect the thickening of the tunica intima than causing pulmonary hypertension. The secretion of MMPs by senescent cells in the skin also contributes to age-related collagen depletion and thinning of the dermal and epidermal layers [48]. SASP was associated with pulmonary artery wall thickening in chronic obstructive pulmonary disease (COPD). Pulmonary artery wall thickening in COPD may result from the paracrine activity of the SASP. The other cause of COPD as a degenerative disease is telomere shortening [49].

\section{The pathological role of SASP in tumorigenesis}

SASP may trigger tumorigenesis that affect cell proliferation, migration and invasion, differentiation, and immune cells or components.

\section{Proliferative effect}

Cell proliferation, especially in premalignant and malignant cells, was induced by SASP components. MMPs, secreted by senescent fibroblasts in breasts, increase the tumorigenicity of breast epithelial cells [50]. In other organs, such as the prostate gland with senescent fibroblasts may secrete connective tissue growth factor (CTGF) or IGFB-rP2, that trigger prostate tumor progression [51,52]. CXCL-1 and IL-8 are expressed in senescent melanocyte cells, then stimulate the CXCR2 receptor on malignant melanocyte cells to proliferate and form melanoma [53]. Another example of the proliferative effect of SASP can be seen in the angiogenesis process. The proliferation of endothelial cells is stimulated by IL-8, MCP-1 and -2, CXCL-1, PGE2, VEGF, EGF, CSFs, u-/tPA MMPs, fibronectin, and laminin as the proangiogenic molecules secreted by senescent cells $[33,54,55]$.

\section{Effect of cell migration and invasion}

Cell migration and invasion are caused by chemokine components in SASP which are secreted by senescent cells. FGF in pancreatic cancer, IL-6 and IL-8 in breast fibroblasts (in breast cancer), and MMP-2 and MMP-3 secreted by senescent cells promote the invasion of these cells. Proteases such as UPA and PAI1, as regulators of UPA, also play a role in cancer cell invasion. In neoangiogenesis, 
endothelial motility and invasion are increased in the presence of senescent fibroblasts that secrete VEGF and chemokines [56,57].

\section{Effect on cell differentiation}

SASP components such as MMP-3, IL-6, IL8, HGF, uPAR can alter epithelial cells lead to differentiation failure (de-differentiated) $[32,58]$. Senescent $\mathrm{T}$ lymphocyte cells cannot proliferate and differentiate as a response to $\mathrm{T}$ cell receptor stimulation. It is believed that upregulation of $\mathrm{C} /$ $\mathrm{EBP} \alpha$ in senescent $\mathrm{T}$ cells is the main cause of this phenomenon. In the physiologist condition C/EBP $\alpha$, a gene that regulates differentiation, is not expressed by $\mathrm{T}$ lymphocytes, except for hematopoietic stem cells, neutrophils, and macrophages. Upregulation of this gene in senescence $\mathrm{T}$ led to failure of $\mathrm{T}$ cell differentiation and increased secretion of inflammatory cytokines IL- 6 and $\mathrm{TNF} \alpha$, which are involved in the aggravation of metabolic and degenerative diseases [59].

\section{Effect on immune cells or components}

SASP can recruit the immune cells to eliminate senescent cells and surrounding damaged cells, which also occurs in tumors. MCP-1 and IL-8 are examples of SASP components that play a role in tumor cell destruction. The de-differentiating effect of SASP occasionally causes monocytes to fail to differentiate into macrophages, reducing the immune response. Other immune cells such as NK cells, neutrophils, eosinophils, dendritic cells, B cells, and $\mathrm{T}$ lymphocytes that infiltrate the tumor are affected by the SASP component $[33,60]$.

The duration of the senescent cells present in the tissue is an important factor in developing both positive and negative effects of SASP secretion on surrounding tissues. In young individuals, SASPs secreted are localized, short in duration, and limited. This condition can potentially eliminate senescent cells, especially in the presence of good support from the immune systems. The negative effects of SASP can occur in obesity (due to chronic inflammation) and in decline functional body systems due to aging [27,39,61].

\section{Conclusion}

Cellular senescence is a condition in which cells cannot divide due to the cessation of the cell cycle caused by various factors, especially DNA damage and exposure to oncogenic stress. One of the cellular senescence main characteristics is the senescence-associated secretory phenotype (SASP). SASP is the secretion of highly variable pro-inflammatory components in tissues by senescent cells.

SASP benefits to tissues, especially as a tumor suppressor, immune clearance, and as a factor that helps tissue repair. On the other hand, secretion of SASP can be detrimental, mainly due to the pro-inflammatory effect, which results in the degenerative phenotype of a tissue closely related to degenerative diseases. Moreover, SASP is also involved in tumorigeneses such as increased cell proliferation, cell migration and invasion, inhibiting the differentiation process and inhibiting the immune mechanism against tumors.

Utilizing the mechanism of action of the senescent cell for inhibiting the proliferation of the malignant cells is promising to be developed. However, the senescence process is also accompanied by various other phenotypes, including SASP which also have a detrimental effect, especially on the environment around the senescent cell. The increasing number of senescent cells has an impact on increasing SASP secretion which can initiate and stimulate the progression of degenerative diseases and tumorigenesis. Researches about senolytic agents have currently been developed to prevent the negative effects of SASP on the senescence process for normal tissues around senescent cells.

\section{Acknowledgment}

The authors thank to Ministry of Research, Technology and Higher Education Republic of Indonesia for the "Penelitian Dasar Unggulan Perguruan Tinggi" grant (Grant number: NKB120/UN2.RST/HKP.05.00/2021). 


\section{Author contributions}

Conceptualization, NSH; Methodology, NSH, FVIdL; Investigation, FVIdL; Resources, NSH; Writing - Original Draft, FVIdL, NSH; Writing Review \& Editing, FVIdL, NSH; Supervision, NSH.

\section{Declaration of interest}

The authors do not have any conflict of interest.

Received: 15 September 2021

Accepted: 21 November 2021

Published online: 31 December 2021

\section{References}

1. Salminen A, Kauppinen A, Kaarniranta K. Emerging role of $\mathrm{NF}-\mathrm{KB}$ signaling in the induction of senescence-associated secretory phenotype (SASP). Cell Signal. 2012;24: 835845. https://doi.org/10.1016/j.cellsig.2011.12.006

2. Byun H-O, Lee Y-K, Kim J-M, Yoon G. From cell senescence to age-related diseases: differential mechanisms of action of senescence-associated secretory phenotypes. BMB Rep. 2015;48: 549-558. https://doi.org/10.5483/ BMBRep.2015.48.10.122

3. Walters HE, Cox LS. Generation of a novel model of primary human cell senescence through Tenovin-6 mediated inhibition of sirtuins. Biogerontology. 2019;20: 303-319. https://doi.org/10.1007/s10522-018-09792-0

4. Bernadotte A, Mikhelson VM, Spivak IM. Markers of cellular senescence. Telomere shortening as a marker of cellular senescence. Aging (Albany, NY). 2016;8: 3-11. https://doi.org/10.18632/aging.100871

5. Srinivas N, Rachakonda S, Kumar R. Telomeres and telomere length: A general overview. Cancers (Basel). 2020;12. https://doi.org/10.3390/cancers12030558

6. Wang B, Kohli J, Demaria M. Senescent cells in cancer therapy: friends or foes? Trends Cancer. 2020;6: 838857. https://doi.org/10.1016/j.trecan.2020.05.004

7. Herranz N, Gil J. Mechanisms and functions of cellular senescence. J Clin Invest. 2018;128: 1238-1246. https:// doi.org/10.1172/JCI95148

8. Amaya-Montoya M, Pérez-Londoño A, Guatibonza-García V, Vargas-Villanueva A, Mendivil CO. Cellular Senescence as a Therapeutic Target for Age-Related Diseases: A Review. Adv Ther. 2020;37: 1407-1424. https://doi. org/10.1007/s12325-020-01287-0

9. Kumari R, Jat P. Mechanisms of cellular senescence: cell cycle arrest and senescence associated secretory phenotype. Front Cell Dev Biol. 2021;9: 645593. https:// doi.org/10.3389/fcell.2021.645593

10. Collado M, Blasco MA, Serrano M. Cellular senescence in cancer and aging. Cell. 2007;130: 223-233. https:// doi.org/10.1016/j.cell.2007.07.003
11. Campisi J. Senescent cells, tumor suppression, and organismal aging: good citizens, bad neighbors. Cell. 2005;120: 513-522. https://doi.org/10.1016/j. cell.2005.02.003

12. Takahashi A, Ohtani N, Yamakoshi K, Iida S, Tahara H, Nakayama K, et al. Mitogenic signalling and the p16INK4a$\mathrm{Rb}$ pathway cooperate to enforce irreversible cellular senescence. Nat Cell Biol. 2006;8: 1291-1297. https:// doi.org/10.1038/ncb1491

13. Yang J, Xu Z-P, Huang Y, Hamrick HE, Duerksen-Hughes PJ, Yu Y-N. ATM and ATR: sensing DNA damage. World J Gastroenterol. 2004;10: 155-160. https://doi.org/10.3748/ wjg.v10.i2.155

14. Lopes-Paciencia S, Saint-Germain E, Rowell M-C, Ruiz AF, Kalegari P, Ferbeyre G. The senescence-associated secretory phenotype and its regulation. Cytokine. 2019;117: 15-22. https://doi.org/10.1016/j.cyto.2019.01.013

15. van Deursen JM. The role of senescent cells in ageing. Nature. 2014;509: 439-446. https://doi.org/10.1038/ nature 13193

16. Schafer MJ, Zhang X, Kumar A, Atkinson EJ, Zhu Y, Jachim $S$, et al. The senescence-associated secretome as an indicator of age and medical risk. JCI Insight. 2020; https://doi.org/10.1172/jci.insight.133668

17. Chambers CR, Ritchie S, Pereira BA, Timpson P. Overcoming the senescence-associated secretory phenotype (SASP): a complex mechanism of resistance in the treatment of cancer. Mol Oncol. 2021;15: 3242-3255. https://doi. org/10.1002/1878-0261.13042

18. Liu M, Yuan T, Liu H, Chen P. CCAAT/enhancer-binding protein $\beta$ regulates interleukin-6-induced transmembrane and ubiquitin-like domain containing 1 gene expression in hepatocytes. Mol Med Rep. 2014;10: 2177-2183. https:// doi.org/10.3892/mmr.2014.2457

19. Cuollo L, Antonangeli F, Santoni A, Soriani A. The Senescence-Associated Secretory Phenotype (SASP) in the Challenging Future of Cancer Therapy and AgeRelated Diseases. Biology (Basel). 2020;9. https://doi. org/10.3390/biology9120485

20. Sebban H, Yamaoka S, Courtois G. Posttranslational modifications of NEMO and its partners in NF-kappaB signaling. Trends Cell Biol. 2006;16: 569-577. https:// doi.org/10.1016/j.tcb.2006.09.004

21. Wu Z-H, Wong ET, Shi Y, Niu J, Chen Z, Miyamoto S, et al. ATM- and NEMO-dependent ELKS ubiquitination coordinates TAK1-mediated IKK activation in response to genotoxic stress. Mol Cell. 2010;40: 75-86. https:// doi.org/10.1016/j.molcel.2010.09.010

22. Coulthard LR, White DE, Jones DL, McDermott MF, Burchill SA. p38(MAPK): stress responses from molecular mechanisms to therapeutics. Trends Mol Med. 2009;15: 369-379. https://doi.org/10.1016/j.molmed.2009.06.005

23. Dodeller F, Gottar M, Huesken D, Iourgenko V, Cenni B. The lysosomal transmembrane protein $9 \mathrm{~B}$ regulates 
the activity of inflammatory signaling pathways. J Biol Chem. 2008;283: 21487-21494. https://doi.org/10.1074/ jbc.M801908200

24. Acosta JC, Banito A, Wuestefeld T, Georgilis A, Janich P, Morton JP, et al. A complex secretory program orchestrated by the inflammasome controls paracrine senescence. Nat Cell Biol. 2013;15: 978-990. https://doi.org/10.1038/ ncb2784

25. Liu G, Zhang F, Lee J, Dong Z. Selective induction of interleukin-8 expression in metastatic melanoma cells by transforming growth factor-beta 1. Cytokine. 2005;31: 241-249. https://doi.org/10.1016/j.cyto.2005.03.008

26. Kang C, Xu Q Martin TD, Li MZ, Demaria M, Aron L, et al. The DNA damage response induces inflammation and senescence by inhibiting autophagy of GATA4. Science. 2015;349: aaa5612. https://doi.org/10.1126/science. aаa5612

27. Borodkina AV, Deryabin PI, Giukova AA, Nikolsky NN. "social life" of senescent cells: what is SASP and why study it? Acta Naturae. 2018;10: 4-14. https://doi. org/10.32607/20758251-2018-10-1-4-14

28. Salminen A, Kaarniranta K. Control of p53 and NF- $\kappa B$ signaling by WIP1 and MIF: role in cellular senescence and organismal aging. Cell Signal. 2011;23: 747-752. https:// doi.org/10.1016/j.cellsig.2010.10.012

29. Liu F, Wu S, Ren H, Gu J. Klotho suppresses RIG-Imediated senescence-associated inflammation. Nat Cell Biol. 2011;13: 254-262. https://doi.org/10.1038/ncb2167

30. Cánepa ET, Scassa ME, Ceruti JM, Marazita MC, Carcagno AL, Sirkin PF, et al. INK4 proteins, a family of mammalian CDK inhibitors with novel biological functions. IUBMB Life. 2007;59: 419-426. https://doi. org/10.1080/15216540701488358

31. Cheung CT, Kaul SC, Wadhwa R. Molecular bridging of aging and cancer: A CARF link. Ann N Y Acad Sci. 2010;1197: 129-133. https://doi.org/10.1111/j.17496632.2009.05392.x

32. Davalos AR, Coppe J-P, Campisi J, Desprez P-Y. Senescent cells as a source of inflammatory factors for tumor progression. Cancer Metastasis Rev. 2010;29: 273283. https://doi.org/10.1007/s10555-010-9220-9

33. Coppé J-P, Desprez P-Y, Krtolica A, Campisi J. The senescenceassociated secretory phenotype: the dark side of tumor suppression. Annu Rev Pathol. 2010;5: 99-118. https:// doi.org/10.1146/annurev-pathol-121808-102144

34. Dasgupta J, Kar S, Liu R, Joseph J, Kalyanaraman B, Remington SJ, et al. Reactive oxygen species control senescence-associated matrix metalloproteinase- 1 through c-Jun-N-terminal kinase. J Cell Physiol. 2010;225: 5262. https://doi.org/10.1002/jcp.22193

35. Kuilman T, Michaloglou C, Vredeveld LCW, Douma S, van Doorn R, Desmet CJ, et al. Oncogene-induced senescence relayed by an interleukin-dependent inflammatory network. Cell. 2008;133: 1019-1031. https://doi. org/10.1016/j.cell.2008.03.039
36. Reichenstein M, Reich R, LeHoux J-G, Hanukoglu I. ACTH induces TIMP-1 expression and inhibits collagenase in adrenal cortex cells. Mol Cell Endocrinol. 2004;215: 109-114. https://doi.org/10.1016/j.mce.2003.11.011

37. Cesari M, Pahor M, Incalzi RA. Plasminogen activator inhibitor-1 (PAI-1): a key factor linking fibrinolysis and age-related subclinical and clinical conditions. Cardiovasc Ther. 2010;28: e72-91. https://doi.org/10.1111/j.17555922.2010.00171.x

38. Rajpathak SN, Gunter MJ, Wylie-Rosett J, Ho GYF, Kaplan $\mathrm{RC}$, Muzumdar R, et al. The role of insulin-like growth factor-I and its binding proteins in glucose homeostasis and type 2 diabetes. Diabetes Metab Res Rev. 2009;25: 3-12. https://doi.org/10.1002/dmrr.919

39. Campisi J. Aging, cellular senescence, and cancer. Annu Rev Physiol. 2013;75: 685-705. https://doi.org/10.1146/ annurev-physiol-030212-183653

40. Hinds P, Pietruska J. Senescence and tumor suppression. [version 1; peer review: 2 approved]. F1000Res. 2017;6: 2121. https://doi.org/10.12688/f1000research.11671.1

41. Kortlever RM, Higgins PJ, Bernards R. Plasminogen activator inhibitor-1 is a critical downstream target of p53 in the induction of replicative senescence. Nat Cell Biol. 2006;8: 877-884. https://doi.org/10.1038/ ncb1448

42. Zhang W, Ling D, Tan J, Zhang J, Li L. Expression of urokinase plasminogen activator and plasminogen activator inhibitor type-1 in ovarian cancer and its clinical significance. Oncol Rep. 2013;29: 637-645. https:// doi.org/10.3892/or.2012.2148

43. Pereira BI, Devine OP, Vukmanovic-Stejic M, Chambers ES, Subramanian P, Patel N, et al. Senescent cells evade immune clearance via HLA-E-mediated NK and CD8+ T cell inhibition. Nat Commun. 2019;10: 2387. https:// doi.org/10.1038/s41467-019-10335-5

44. Gurtner GC, Werner S, Barrandon Y, Longaker MT. Wound repair and regeneration. Nature. 2008;453: 314-321. https://doi.org/10.1038/nature07039

45. Gieseck RL, Wilson MS, Wynn TA. Type 2 immunity in tissue repair and fibrosis. Nat Rev Immunol. 2018;18: 62-76. https://doi.org/10.1038/nri.2017.90

46. Lee S, Ahad A, Luu M, Moon S, Caesar J, Cardoso WV, et al. CCN1-Yes-Associated Protein Feedback Loop Regulates Physiological and Pathological Angiogenesis. Mol Cell Biol. 2019;39. https://doi.org/10.1128/MCB.00107-19

47. Jun J-I, Lau LF. The matricellular protein CCN1 induces fibroblast senescence and restricts fibrosis in cutaneous wound healing. Nat Cell Biol. 2010;12: 676-685. https:// doi.org/10.1038/ncb2070

48. Campisi J, Andersen JK, Kapahi P, Melov S. Cellular senescence: a link between cancer and age-related degenerative disease? Semin Cancer Biol. 2011;21: 354359. https://doi.org/10.1016/j.semcancer.2011.09.001

49. Noureddine H, Gary-Bobo G, Alifano M, Marcos E, 
Saker M, Vienney N, et al. Pulmonary artery smooth muscle cell senescence is a pathogenic mechanism for pulmonary hypertension in chronic lung disease. Circ Res. 2011;109: 543-553. https://doi.org/10.1161/ CIRCRESAHA.111.241299

50. Liu D, Hornsby PJ. Senescent human fibroblasts increase the early growth of xenograft tumors via matrix metalloproteinase secretion. Cancer Res. 2007;67: 31173126. https://doi.org/10.1158/0008-5472.CAN-06-3452

51. Kim K-H, Park G-T, Lim Y-B, Rue S-W, Jung J-C, Sonn J-K, et al. Expression of connective tissue growth factor, a biomarker in senescence of human diploid fibroblasts, is up-regulated by a transforming growth factor-betamediated signaling pathway. Biochem Biophys Res Commun. 2004;318: 819-825. https://doi.org/10.1016/j. bbrc.2004.04.108

52. Yang F, Tuxhorn JA, Ressler SJ, McAlhany SJ, Dang TD, Rowley DR. Stromal expression of connective tissue growth factor promotes angiogenesis and prostate cancer tumorigenesis. Cancer Res. 2005;65: 8887-8895. https:// doi.org/10.1158/0008-5472.CAN-05-1702

53. Dhawan P, Richmond A. Role of CXCL1 in tumorigenesis of melanoma. J Leukoc Biol. 2002;72: 9-18.

54. Coppé J-P, Kauser K, Campisi J, Beauséjour CM. Secretion of vascular endothelial growth factor by primary human fibroblasts at senescence. J Biol Chem. 2006;281: 2956829574. https://doi.org/10.1074/jbc.M603307200
55. Tonini T, Rossi F, Claudio PP. Molecular basis of angiogenesis and cancer. Oncogene. 2003;22: 6549-6556. https://doi. org/10.1038/sj.onc.1206816

56. Coppé J-P, Patil CK, Rodier F, Sun Y, Muñoz DP, Goldstein $\mathrm{J}$, et al. Senescence-associated secretory phenotypes reveal cell-nonautonomous functions of oncogenic RAS and the p53 tumor suppressor. PLoS Biol. 2008;6: 28532868. https://doi.org/10.1371/journal.pbio.0060301

57. Parrinello S, Coppe J-P, Krtolica A, Campisi J. Stromalepithelial interactions in aging and cancer: senescent fibroblasts alter epithelial cell differentiation. J Cell Sci. 2005;118: 485-496. https://doi.org/10.1242/jcs.01635

58. Birch J, Gil J. Senescence and the SASP: many therapeutic avenues. Genes Dev. 2020;34: 1565-1576. https://doi. org/10.1101/gad.343129.120

59. Nakagami H. Cellular senescence and senescence-associated T cells as a potential therapeutic target. Geriatr Gerontol Int. 2020;20: 97-100. https://doi.org/10.1111/ggi.13851

60. Nesbit M, Schaider H, Miller TH, Herlyn M. Low-level monocyte chemoattractant protein-1 stimulation of monocytes leads to tumor formation in nontumorigenic melanoma cells. J Immunol. 2001;166: 6483-6490. https:// doi.org/10.4049/jimmunol.166.11.6483

61. Lecot P, Alimirah F, Desprez P-Y, Campisi J, Wiley C. Context-dependent effects of cellular senescence in cancer development. Br J Cancer. 2016;114: 1180-1184. https:// doi.org/10.1038/bjc.2016.115 